Session 2525

\title{
Linking Mechanics and Materials in Structural Design: A Generalized Design Template and its Application
}

\author{
C. H. Jenkins, S. K. Khanna \\ Mechanical Engineering Department \\ South Dakota School of Mines and Technology \\ Rapid City, SD 57701 USA
}

\begin{abstract}
Engineering education follows much of what we do in engineering practice itself, for better or worse. One common activity that we must approach with great care in either field is the decomposition of complex processes into smaller, simpler, more manageable parts. However, the educator and engineer must always be aware of what may be lost in the decoupling process. We educate students in structural design in this way. It is typical to have separate and distinct course in applied mechanics, materials science, and engineering design. This certainly simplifies the approach to teaching (and perhaps learning) the subject. But the division is wholly artificial, since real, complex structures are a result of an interaction between mechanics, materials, and design. Parallel consideration of all three components is the only way to achieve an optimum structure. Recently, under support from the National Science Foundation and the State of South Dakota, the authors have undertaken a project to link these 3 subjects within a newly developed course in structural design. Central to the linkage of mechanics, materials, and design is the concept of a generalized design template (GDT). The GDT provides a framework for input and output of all data in a process of total structural design. It allows for problem definition, identification of design degrees of freedom and the associated design space, conceptual design activities, and detailed design analysis. The GDT is embedded within a MathCAD workbook. The student has access to worksheets, as well as geometric data, material properties, formulas, etc. Global and local variables can be defined. An example of GDT use is given.
\end{abstract}

I. Introduction

This paper is concerned with two interconnected activities:

- Bridging the divide in teaching the art and science of structural design

- Bridging the divide between applied mechanics and materials science

First, a few words about structures and structural design are in order. A structure broadly construed is any physical body that must carry loads, and hence develops stresses and strains. The primary engineering disciplines that design structures are aerospace, civil, and mechanical engineering. Aerospace structural engineers design airplanes, rockets, satellites, and the like. Civil structural engineers design buildings, highways, and bridges. Mechanical structural engineers design machinery, vehicles, and consumer products. From a structures perspective, there is much more in common in what aerospace, civil, and mechanical structural engineers do than there is different. 
This paper discusses our current attempts to provide a unifying pedagogic treatment that bridges the art and science of structural design. Modern design concepts are introduced. We consider structural engineering in the broadest and most general sense, and it is important that the structural engineering student learn from the design of structures in all applications, in or out of their discipline. A wing truss, bridge girder, or overhead crane trolley are all close relatives of the same family of structures. Certainly the design practices of the specific discipline must by learnt, but early on it is much more important to design structures generally. To become a great painter, we don't want to always paint bowls of fruit!

The other divide to be bridged is that between applied mechanics and materials science. In an earlier time, perhaps there was much less gap to be closed. The onset of specialization and the rapid rise of technology, however, have created separate disciplines concerned with the deformation of solid materials. At the expense of over simplifying: mechanics is physics and materials science is chemistry. But in the deformation of a real body, the macroscopic loads, boundary conditions, and geometry interact with the material microstructure - any separation otherwise is ours alone, not natures!

The typical undergraduate engineering curriculum follows along this schism. An introductory course in "mechanics of materials" is taught by mechanics faculty, whereas an introductory course in "property of materials" is taught by science faculty. Mostly, such courses are taught in isolation from one another, both philosophically (in different "languages" and points of view) and physically (the faculty don't interact). (That the instructors are competent in their respective disciplines and teach their courses well is assumed.) But such a separation is purely artificial, and the student misses out in never seeing the intimate connection between the macroscopic and microscopic domains of the problem. Society loses out by not having at their service efficient, high-performance material/structural systems.

\section{A new approach}

In order to mend the deficiencies in the way mechanics, materials, and design are taught as separate disciplines, we have developed a new approach to the subject of structural design (with the support of the National Science Foundation and the State of South Dakota). The approach is embodied in a new course titled Mechanics and Materials in Structural Design. The course is currently taught at the $3^{\text {rd }}$ year undergraduate level, after the students have had some basic introduction (albeit non-integrated) to mechanics, materials, and engineering design. A companion textbook and multimedia courseware are also under development ${ }^{1-9}$.

We follow a very methodological process to introduce and integrate mechanics, materials, and design issues continuously throughout the course. We engage the actual design of structures very early by first providing a generalized design template, which can be followed and specified for various structural applications. Links between mechanics and materials quantities are emphasized, primarily through the standardized mechanical property tests. Numerous realistic example design problems are used, so students may get a sense of how real, complex structures are designed. Problems are provided from aerospace, civil, and mechanical applications. 
This course seeks to present structural design in a very broad and integrated context, what we call total structural design. This encompasses not just mechanics issues, such as the analysis of stress and strain, but materials issues and manufacture/assembly issues as well. Hence we think of a structure as an integrated material/structural system, designed with cradle-to-grave considerations.

In this course, the students:

- Learn about fundamental mechanics or macroscopic concepts such as stress, strain, and moment of inertia

- Learn about fundamental materials or microscopic concepts such as atomic structure and bonding, defect theory, and measurement of material properties ${ }^{2}$

- Learn about the intimate linkage between macroscopic and microscopic concepts, and the impact of this integration on the design of structures ${ }^{2}$

- Learn how to apply a generalized design template in the design of structures

- Learn how to manipulate design degrees of freedom to achieve an optimal structural design

- Learn about the different classes of structures and their special design considerations

- Learn about simultaneous engineering of materials and structures.

III. The design space

Design is a creative human endeavor that is the essence of engineering. Design is an activity that turns the abstract information about the need for a product or process into concrete knowledge about how to realize that product or process. Design sits at the intersection of science, art, business, politics, and psychology. Design solutions are non-unique: different engineers will arrive at different design solutions; some will be better solutions than others, but there is no single, correct solution to any design problem.

This last point is important, because it leads us to define a critical concept, the design solution space. Before we describe this abstract space, however, we step back and think about physical space, for example the space of our physical environment. We usually define 3-dimensional physical space by a set of 3 coordinates, say $x-y-z$. Indoors, the intersection of two walls and the floor quite nicely forms the coordinate axes of that physical space.

We can now think of the physical space as being defined by the coordinates, and consequently define a variety of solutions in this space, e.g., the trajectory of a particle to given excitation. If that trajectory depended on each of the coordinates independently, then we would say the particle had 3 coordinate degrees of freedom (CDOF).

A set of coordinates can thus define a space, and this space can be physical or abstract. Thus in a like manner, we will use a variety of quantities as generalized coordinates to define the design space. For example, we might have a design problem where we consider only member crosssectional area $\mathrm{A}$, tensile yield strength $\mathrm{S}_{\mathrm{yt}}$, and cost $\$$. (The first quantity, $\mathrm{A}$, is a mechanics degree of freedom, $\mathrm{S}_{\mathrm{yt}}$ is a material degrees of freedom, while cost is a performance degree of freedom.) 
We would look for a solution inside this design space. Most likely, we would also constrain this space, as in the particle problem, by placing limits on cost, for example, say $\$<\$_{\max }$, some maximum cost. The important point is that each of these "degrees of freedom" can be manipulated within limits to achieve the best design solution.

We can then talk of design degrees of freedom ( $D D O F)$, in a manner similar to speaking of coordinate degrees of freedom. Of course, in any realistic problem the number of DDOF could be quite large, which would no longer let us easily draw the space, but we can none the less still think of it in these terms. Table 1 organizes the design degrees of freedom, degrees of freedom that can ultimately be manipulated in seeking the design solution.

\begin{tabular}{|l|l|l|}
\hline \multicolumn{1}{|c|}{ Type of DDOF } & \multicolumn{1}{|c|}{ Example DDOF } & \multicolumn{1}{c|}{ DDOF description } \\
\hline \multirow{3}{*}{ Mechanics } & Geometry & Length, area, moment of inertia \\
\cline { 2 - 3 } & Boundary condition & Translation, rotation \\
\cline { 2 - 3 } & Load & Type, magnitude, direction \\
\hline \multirow{3}{*}{ Material } & Weight & Mass density \\
\cline { 2 - 3 } & Modulus & Tensile, shear \\
\cline { 2 - 3 } & Strength & Yield, ultimate \\
\hline \hline \multirow{3}{*}{ Performance } & Cost & Life cycle, payback \\
\cline { 2 - 3 } & Precision & Tolerance, stack-up \\
\cline { 2 - 3 } & Robustness & Resilience, factor of safety \\
\hline
\end{tabular}

Table 1. Examples of design degrees of freedom.

IV. Total structural design

Modern design encompasses life-cycle design, in that the entire product life-cycle is considered, from "cradle to grave." For example, in the design of a product, considerations may be given to resources required to:

- extract and process raw materials

- analyze product response

- manufacture, assemble, and maintain the product

- remove the product from service

Modern design is carried out by interdisciplinary teams, with many of the design activities carried out concurrently, or in parallel. This is in contrast to the practice of sequential design, often called "throw it over the wall" design. Concurrent design relies upon strong communication, such as detailed and shared databases, and groups of diverse people working together for common purpose as a team. (A team is a collection of people who are united by a mutually shared commitment to a common goal, who have complementary skills, and who hold one another mutually accountable for the attainment of that goal.)

If a structure is required as part of the design, then that structure must be considered within the context of the entire design process. This is what we refer to as total structural design. It is not enough to consider that the structure carries loads safely. The engineer must also consider:

- how the structure interfaces with other elements of the design 
- how the manufacture and assembly of the structure can be made most cost-effective

- how the maintenance and repair of the structure can be made most cost-effective

- how the structure contributes to cost and weight budgets for the design

Material selection follows the methods of Ashby and co-workers ${ }^{10}$. However, we augment Ashby's method by use of a decision matrix approach to determining the best materials from among a group of relevant choices. The decision matrix allows not only for scoring how various materials satisfy design criteria, but allows for the weighting of the relative importance of the criteria.

V. The generalized design template

We provide a template or pattern for the design of structures. This template is sufficiently general enough to be used for the design of any structure. It covers three basic activities of the design process: problem definition, preliminary or conceptual design, and detailed design. In the course, we adapt the template to the design of specific structures. The template has been developed as a Mathcad "workbook" for ease of combining design and analysis in practice.

\section{Problem Definition}

Goal: Begin to define the design space

- Define the service environment: loads, configurations, physical environment, system interactions, level of uncertainty

- Define performance requirements: weight, longevity, safety factor, robustness, ...

- Define service environment: loads, physical environment, system interactions, levels of uncertainty, ...

- Define project constraints: cost targets, time targets, physical constraints (manufacturing limitations, assembly limitations, ...), system interaction constraints (interfacing constraints, load sharing, ...)

Preliminary Design

Goal: Manipulate design degrees of freedom (ddof) to determine a reasonable preliminary solution in the design space

- Define the basic ddof:

Basic ddofs: $\quad$ Material Properties:

\begin{tabular}{|c|c|c|}
\hline $\begin{array}{l}* \text { geometry } \\
* \text { density } \\
* \text { strength } \\
* \text { stiffness }\end{array}$ & $\begin{array}{c}\text { mechanics/materials } \\
\text { linkage }\end{array}$ & $\begin{array}{l}* \text { What are they? } \\
* \text { How are they measured? } \\
* \text { Why do they exist? } \\
* \text { How can they be manipulated? } \\
* \text { How are they related? }\end{array}$ \\
\hline
\end{tabular}

Figure 1. Defining the basic DDOFs. 
- Perform trade study: investigate various trades (compromises) among the ddof, use decision matrix

- Perform a failure modes effects analysis (FMEA)

\section{Detailed Design}

Goal: Provide the information (specifications, tolerances, materials, graphics, ...) necessary to achieve the design in an optimal manner

- Consider:

$>$ boundary conditions: contact, crushing, stress concentrations, ...

$>$ attachments: joining, stress concentrations, weight, ...

$>$ materials: corrosion, fatigue, manufacturability, engineer the material, ...

$>$ life cycle: cost, recyclability, maintainability, repairability, ...

$>$ optimization: with respect to specs., constraints, other trades, ...

- Define advanced ddofs:

$>\mathrm{CTE}$

$>$ Fracture toughness

$>$ Impact resilence

$>$ Hardness

$>$ Fatigue strength

$>$ Creep compliance/relaxation modulus

$>$ Ductility

$>$ Thermal conductivity

$>$ Corrosion resistance

$>$ Abrasion resistance

- Perform trades studies as required, use decision matricies

VI. An example design problem

To demonstrate the approach, we consider the following example design problem:

A large manufacturing facility has ten identical heavy machine tools, each weighing $90 \mathrm{kN}$ (about 10 ton), that need to be elevated above a low-strength concrete floor by about $15 \mathrm{~cm}$ for cleaning purposes. (It is desired to hose down the floor with an alkaline solvent.)

The machines currently have a "foot" on each corner, which is comprised of a cylindrical pad of $13 \mathrm{~mm}$ radius by $7 \mathrm{~mm}$ depth made from A-36 steel (see the sketch below).

Design a set of 4 inexpensive supports per machine (40 total) to accomplish the elevation, with a factor of safety of 2. The existing "foot" should sit atop the support in each case. 


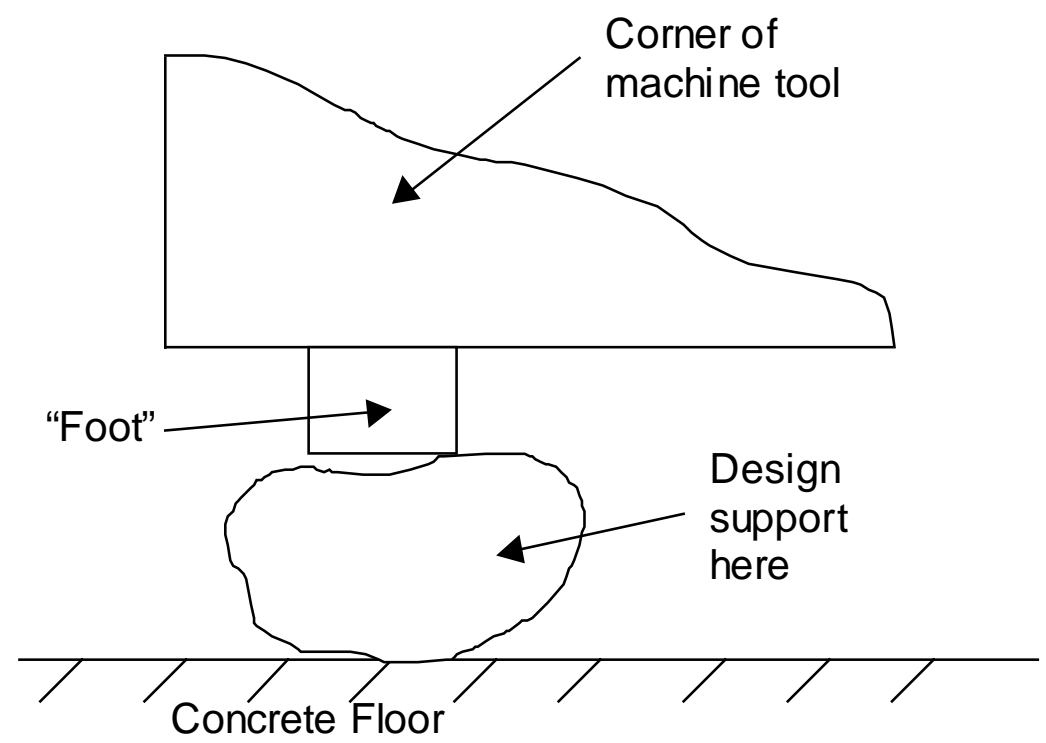

\section{Problem Definition}

Performance requirements:

- Factor of Safety = 2; this a specification on strength, and as such is of primary importance. Then $\sigma \leq S_{\mathrm{f}} / 2$, where $S_{\mathrm{f}}$ is some as yet unspecified failure strength.

No other performance requirements are given.

Service environment:

- Loads - are assumed to act statically. It can be assumed that the load per support is $1 / 4$ the weight of a machine or

$$
\mathrm{P}=1 / 4(90 \mathrm{kN})=22.5 \mathrm{kN}
$$

(The assumption of static loads is made to keep the problem simple enough for educational purposes. In the real situation, the loads would clearly be dynamic.)

- There is a concern about the support being exposed to solvent.

No other service environment specifications are given.

Project constraints:

- Low cost (implies generally available material, simplicity of design, ease of manufacture and assembly, reasonably low weight, etc.), particularly due to the large number of parts required.

- Existing strength of the concrete floor is low.

No other constraints are given.

\section{Preliminary Design}

- Identify ddofs:

1. Geometry minimize volume to keep weight low, keep slenderness ratio $<10$, keep contact stress low area A and length $L$ as ddofs 
2. Density keep weight low $(\mu)$

3. Strength design for yielding where possible for low cost $\left(\mathrm{S}_{\mathrm{y}}\right)$; concrete strength is $\mathrm{S}_{\mathrm{u}}$

4. Stiffness modulus (E)

5. Boundary conditions pinned bc can keep link axial, i.e., without moment reactions (more details about the connections will not be considered at this stage)

- Trade study: The desire to keep costs low (and as always to keep things as simple as possible!) suggests a simple axial structure for the support. A circular cross-section of diameter $\mathrm{D}$ will keep the surface area to cross-sectional area of the link to a minimum, thus minimizing the volume of material. Material considerations suggest simple, readily available materials to keep costs low, but analysis needs to confirm the specific choice.

- FMEA: Failure expected to be from 1) simple static fracture of the concrete; 2) yielding due to higher stress at bearing between foot and support; and 3) corrosion failure due to use of alkaline solvent/wash.

\section{Detailed Design}

- Keep slenderness ratio of support < 10 to avoid failure by buckling:

$$
\begin{gathered}
\frac{\mathrm{L}}{\sqrt{\mathrm{I} / \mathrm{A}}}<10, \quad \mathrm{I}=\frac{\pi \mathrm{D}^{4}}{64}, \quad \mathrm{~A}=\frac{\pi \mathrm{D}^{2}}{4} \\
\frac{\mathrm{L}}{\sqrt{\frac{\pi \mathrm{D}^{4}}{64} \frac{4}{\pi \mathrm{D}^{2}}}}=\frac{\mathrm{L}}{\mathrm{D} / 4}=\frac{4 \mathrm{~L}}{\mathrm{D}}<10
\end{gathered}
$$

or

\section{$\underline{\mathrm{L} / \mathrm{D}<2.5}$}

- Keep bearing stress in concrete $<\mathrm{S}_{\mathrm{u}} / \mathrm{FS}$ :

Bearing stress in the concrete $=\mathrm{P} / \mathrm{A} \leq \mathrm{S}_{\mathrm{u}} / \mathrm{FS}=14 \mathrm{MPa} / 2=7 \mathrm{MPa}$

Then solving for A:

$$
\mathrm{A} \geq\left(22.5 \mathrm{kN} / 7 \times 10^{6} \mathrm{~N} / \mathrm{m}^{2}\right)=0.00321 \mathrm{~m}^{2}
$$

Since $A=\pi D^{2} / 4$, the minimum diameter $D$ is then found from the equality case as

$$
\mathrm{D}=4 \mathrm{~A} / \pi=4\left(0.00321 \mathrm{~m}^{2}\right) / \pi=\underline{64 \mathrm{~mm}(2.52 \mathrm{in})}
$$

Now the length of the support can be specified from the L/D ratio:

$$
\mathrm{L} \leq 2.5 \mathrm{D}=2.5(6.4 \mathrm{~cm})=\underline{16 \mathrm{~cm}(6.3 \mathrm{in})}
$$


Note that that the $15 \mathrm{~cm}$ elevation desired is within this range.

At this point, we have defined the minimum geometry for the support, but have yet to specify the material. Two considerations that apply here are corrosion resistance and bearing stress.

- Review possible material choices based on corrosion resistance:

Using the Ashby chart ${ }^{10}$ for comparative ranking of the resistance of materials to attack by different environments, we find that the best possible material choices for resistance against alkali attack are steel, cast iron, titanium, polytetrafluroethylene (PTFE), polypropylene (PP), alumina $\left(\mathrm{Al}_{2} \mathrm{O}_{3}\right)$ - a ceramic, and high density polyethylene (HDPE). Assuming in advance that we will need relatively high strength to withstand the foot bearing stress, we further look to obtain the best possible combination of strength and low cost (this assumption can be checked later). Here we use the strength to relative cost per unit volume Ashby chart and rank the above material choices as follows:

Table 2. Materials selection chart for the design example. Note that a score of 1 indicates the item least favorably satisfies the criteria. A weighting factor of 1 indicates a criteria of least importance.

\begin{tabular}{|c|c|c||c|c|c|}
\hline $\begin{array}{c}\text { Possible materials } \\
\text { from environment } \\
\text { chart }\end{array}$ & \multicolumn{4}{|c|}{$\begin{array}{c}\text { Material ranking from the Ashby Charts } \\
\text { Raw rankings and weighted rankings are given) }\end{array}$} & $\begin{array}{c}\text { Weighted } \\
\text { total }\end{array}$ \\
\hline & $\begin{array}{c}\text { Resistance to Alkali } \\
\text { Attack Rank }\end{array}$ & $\begin{array}{c}\text { Weighted Rank } \\
\text { (Weight =1) }\end{array}$ & $\begin{array}{c}\mathrm{S}_{\mathrm{y}} \text { vs. } \\
\mathrm{C}_{\mathrm{R} \rho} \text { Rank }\end{array}$ & $\begin{array}{c}\text { Weighted Rank } \\
\text { (Weight = 2) }\end{array}$ & \\
\hline Steel & 2 & 2 & 5 & 10 & 12 \\
\hline Cast Iron & 2 & 2 & 5 & 10 & 12 \\
\hline Titanium alloy & 2 & 2 & 2 & 4 & 6 \\
\hline PTFE & 2 & 2 & 1 & 2 & 4 \\
\hline PP & 2 & 2 & 4 & 8 & 10 \\
\hline HDPE & 2 & 2 & 3 & 6 & 8 \\
\hline Alumina & 1 & 1 & 5 & 10 & 11 \\
\hline
\end{tabular}

The best choices are cast iron and steel. However, looking at the Ashby chart it should be noticed that among these materials cast iron is the cheapest of the two.

- Keep bearing stress at foot/support interface $<\mathrm{S}_{\mathrm{y}} / \mathrm{FS}$ :

This will require calculating the maximum bearing stress between the machine foot and the support. As before, we first calculate the bearing area $\mathrm{A}_{\mathrm{f}}$ :

$$
\mathrm{A}_{\mathrm{f}}=\pi \mathrm{D}_{\mathrm{f}}^{2} / 4=\pi\left(25 \times 10^{-3} \mathrm{~m}\right)^{2} / 4=491 \times 10^{-6} \mathrm{~m}^{2}
$$

The bearing stress of the foot on the support is then

$$
\sigma_{\mathrm{z}}=\mathrm{P} / \mathrm{A}_{\mathrm{f}}=22.5 \mathrm{kN} / 491 \times 10^{-6} \mathrm{~m}^{2}=45.8 \mathrm{Mpa}
$$

The required yield strength is then 


$$
\mathrm{S}_{\mathrm{y}}=\sigma_{\mathrm{z}} \mathrm{FS} \approx 92 \mathrm{Mpa}
$$

Any of the 3 candidate materials will easily satisfy this requirement. So we choose the lowest cost material or cast iron.

A few other notes about the design are in order:

- To keep the problem simple, we are assuming here that the machine will be globally stable when sitting upon the supports. In a real design, this would need to be carefully considered, especially since dynamic loads are involved.

- We haven't worried here about esthetics, e.g., whether or not we're going to get rust stains on the concrete from the cast iron. This might be important in certain situations.

The final design is then:

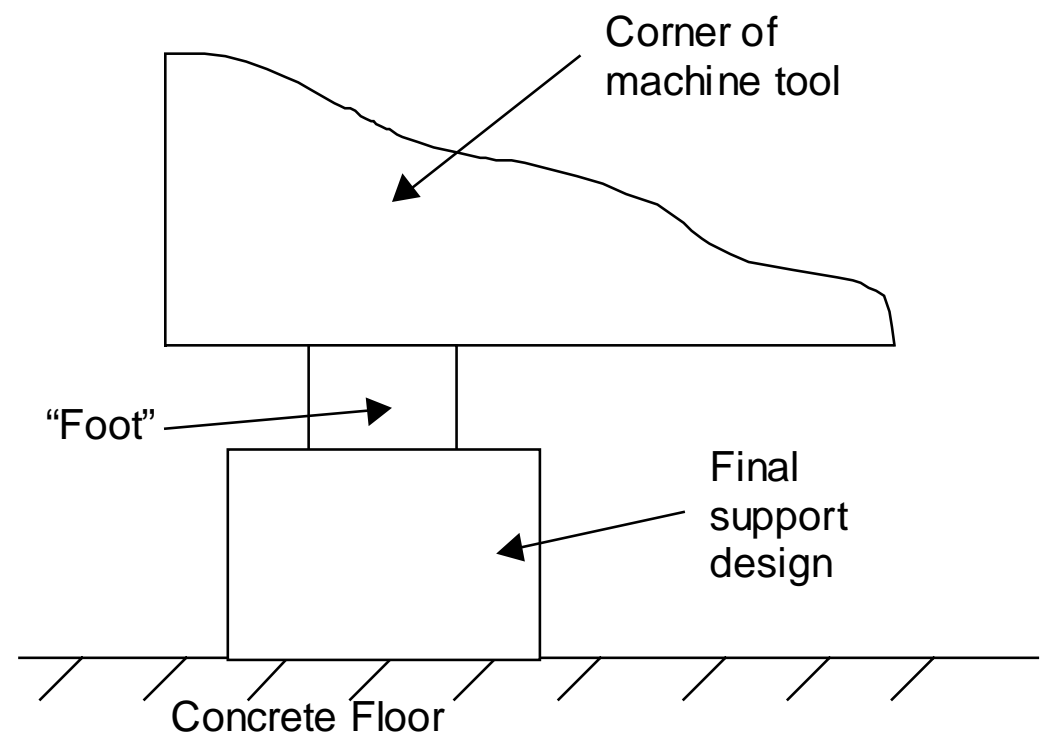

- Final support specification:

\section{$64 \mathrm{~mm}(2.5 \mathrm{in})$ round bar $x 15 \mathrm{~cm}(6 \mathrm{in})$ long cast gray iron}

(Note: since 40 of these need to be made, one might order say 20 - 12 in lengths. These are readily available from manufacturers.)

\section{Acknowledgement}

The authors wish to express their gratitude to the National Science Foundation for their support of this work under award DUE-9972394. 
Session 2525

Bibliography

1. Jenkins, C.H., Khanna, S.K., and Roylance, D. (in review). "Linking Design with Structural Mechanics and M aterials," J Materials: Design and Applications.

2. Khanna, S.K., Jenkins, C.H., and Roylance, D. (in review). "A N ew A pproach to Teaching M echanics and M aterials Science," J Materials: Design and Applications.

3. Roylance, D., Cohen, K., Jenkins, C.H., and K hanna, S.K. (in review). "M echanics of M aterials: A M aterial Science Perspective," J Materials: Design and Applications.

4. Jenkins, C.H. and K hanna, S.K. (2000), "Linking M echanics and M aterials in Structural Design," 2000 ASEE Annual Conference, St. L ouis, MO.

5. Jenkins, C.H. and K hanna, S.K. (2000), "Linking M echanics and M aterials in Engineering Design I: Background and M otivation," Mechanics and Materials in Design 2000, Orlando, FL.

6. K hanna, S.K. and Jenkins, C.H. (2000), "Linking M echanics and M aterials in Engineering D esign II: A N ew A pproach," Mechanics and Materials in Design 2000, Orlando, FL.

7. Roylance, D.K., Jenkins, C.H., and Dieter, G.E. (1999), "The M aterials-M echanics Linkage in the Engineering Curriculum," J . Materials Education 21, 145-148.

8. Roylance, D.K., Jenkins, C.H., and Dieter, G.E. (1998), "The M aterials-M echanics Linkage in the Engineering Curriculum," Workshop on Materials Education, 1998 Meeting Materials Research Society, Boston, MA.

9. Jenkins, C.H. (1997). "On the Linkage of Applied Mechanics and Materials Science in the Engineering Curriculum," 25th Midwestern Mechanics Conf., Rapid City, SD.

10. Ashby, M.F. (1999). Materials Selection in Engineering Design (2ed), Butterworth-Heineman.

\section{CHRISTOPHER H. M. JENKINS}

Dr. Chris Jenkins, P.E., teaches and conducts research in the areas of continuum mechanics, computational and experimental mechanics, mechanical design, and structural dynamics. He is the founder of the Compliant Structures Laboratory at SDSM\&T (www.compliantlab.sdsmt.edu), where he is Professor of Mechanical Engineering. Dr. Jenkins is leading an effort to link mechanics, materials, and design in structural engineering (http://mmd.sdsmt.edu).

\section{SANJEEV K. KHANNA}

Sanjeev Khanna is an Assistant Professor of Mechanical Engineering at the South Dakota School of Mines and Technology in Rapid City, South Dakota. He received his B.S. and M.S. from Indian Institute of Technology, Kanpur, India, and Ph.D. from University of Rhode Island, Kingston, Rhode Island. Dr. Khanna's teaching and research interests are in solid mechanics, experimental mechanics, and design. 